\title{
Increased rate of introduction of non-native plants in China since 2002 driven by intentional introductions
}

\author{
Ming Ni ( $\nabla$ ming.ni@usherbrooke.ca ) \\ Universite de Sherbrooke https://orcid.org/0000-0002-5180-1049 \\ David C Deane \\ La Trobe University - Melbourne Campus: La Trobe University
}

\section{Research Article}

Keywords: Plant invasions, introduction history, first records, introduction pathway

Posted Date: April 14th, 2021

DOI: https://doi.org/10.21203/rs.3.rs-420245/v1

License: (c) (1) This work is licensed under a Creative Commons Attribution 4.0 International License.

Read Full License 


\section{Abstract}

The history of plant introductions in China is inextricably associated with globalization and trade. There have been two periods where China has opened to the world, punctuated by periods of isolation. Here, we compare historical rates of introduction from 1840-2011 and ask how the rate of introduction of nonnative plants has changed and how intentional and non-intentional introductions compare. The highest rate of introductions occurred between 1900 and 1940, where mean annual introduction was 8.7 plant species. Plant introductions post 2002 occurred at the second highest rate, but this was still little over half the earlier period at 4.4 plant species per year. In both periods, intentional introductions contributed the greatest proportion, and intentional and non-intentional introductions shared similar temporal trajectories.

\section{Plant Introductions In The Chinese Context}

China has one of the highest species diversities of any country in the world, but many species are already facing a high extinction risk (He, 2009; Lu et al., 2018). Biological invasion is among the leading threats and is being exacerbated by rapid changes in climate and land use (Ma et al., 2013). The temporal dynamics of plant introductions are thought to reflect China's trade history (Ding et al., 2008; Essl et al., 2011). In the first half of the $20^{\text {th }}$ century, China gradually became less isolated, expanding trade with other countries (Ding et al. 2008), increasing the potential for introduction of non-native plants. National policy limiting trade with the western world then dominated from 1950s to 1970s, presumably reducing the rate of introduction over this period. Since the 1970s reforms, trade and economic activity have increased dramatically, facilitating plant introductions in China again.

However, little is known on how the relative rate of introduction in the early $20^{\text {th }}$ century compares with the years since re-opening post 1970s. Here, we report historical trends in introduction of non-native plants to China from 1840-2011, which we obtained from the comprehensive inventory of naturalized plants in China compiled by Jiang et al. (2011). Species lists were modified following review of the primary sources (Ma et al. 2013; Ma 2014). We excluded native species and 'casual' alien species (i.e., those without established populations in China) yielding 538 naturalized plants. The date of introduction for each species was estimated based on its first reported time in the literature and/or the collection date for the first herbarium specimen present in the Chinese Virtual Herbarium (http://www.cvh.org.cn/), which recorded the collection time and location of the specimens of each species. Further details on data processing are in Ni et al. (2021). The data for first record time and introduction pathway are provided in supplementary material. We calculated a cumulative total of introductions by year of first record, and source of introduction (intentional or unintentional). We then applied segmented linear regression to identify changes in the rate of introduction and report the slope for each identified segment. Segmented regression used R-package 'segmented' (Muggeo, 2003), with starting values for breakpoints set as 1900, 1950 and 2000 , based on patterns in the data. 


\section{Historical And Contemporary Rates Of Introduction Of Non-native Plants In China}

Segmented regression fitted the introduction data well $\left(R^{2}\right.$ adj $\left.>0.99\right)$ and identified four periods where the rate of introduction differed: 1840-1905, 1905-1935, 1935-2002 and 2002-2011 (Table 1, Fig. 1). There were 51 non-native plant species found in China before 1840, most of which were intentionally introduced as food or medicinal plants. The number of introduced species then increased only slowly from 1840 to 1905. After this time however, a steep rise in the rate of introductions saw the majority (45\%) of contemporary non-native species introduced between 1905 and 1935, at an average rate of 8.7 species per year (Fig. 1, Table 1). After 1935, the rate of plant introductions again decreased, before significantly increasing again after 2002, attaining a mean rate of 4.4 species per year (Fig. 1; Table 1). Most nonnative plants were intentionally introduced (68\%), but both intentionally and unintentionally introduced species shared a similar temporal trajectory.

\section{Significance}

Many have highlighted the need to manage the growing bio-invasion risk due to the rapid economic growth and dramatic landscape changes occurring in China (Ding et al., 2008; He, 2009; Early et al, 2016, Huang et al., 2016). Indeed, China faces future invasion risks that rank among the highest in the world (Early et al, 2016; Liu et al., 2019). Interestingly, here we show that rates of introduction are only around half the historical maximum, which was observed during the early $20^{\text {th }}$ century. However, our data do not extend beyond 2011, so we are unable to give a rate for the last decade. Irrespective, there has been a clear increase in the rate of introductions post 2002 and - as was the case in the early $20^{\text {th }}$ century intentional introductions account for the majority of this. While unintentionally introduced plants have a higher risk of creating severe ecological or environmental impacts (Ni et al., in press), it is important that the risk that intentionally introduced species become invasive is not overlooked.

\section{Declarations}

Funding: This work is funded by the program of China Scholarships Council (No. 201806380175).

Author contribution: MN designed the study and collected the data. MN and DD analyzed the data and wrote the manuscript.

Conflicts of interest: No.

Code availability: Not applicable.

Availability of data and material: The data of first record time is provided in Supplementary material.

Ethics approval: Not applicable. 
Consent to participate: Not applicable.

Consent for publication: Not applicable.

Acknowledgments: This work is funded by the program of China Scholarships Council (No. 201806380175).

Data availability statement: All data used in this study are provided in Supplementary Material.

\section{References}

Ding J, Mack RN, Lu P, Ren M, \& Huang H. (2008). China's booming economy is sparking and accelerating biological invasions. Bioscience, 58(4), 317-324.

Early R, Bradley BA, Dukes JS, Lawler JJ, Olden JD, Blumenthal DM, ... Tatem, A. J. (2016). Global threats from invasive alien species in the twenty-first century and national response capacities. Nature Communications, 7, 12485.

He F. (2009). Price of prosperity: economic development and biological conservation in China. Journal of Applied Ecology, 46(3), 511-515.

Huang J, Huang J, Liu C, Zhang J, Lu X, \& Ma K. (2016). Diversity hotspots and conservation gaps for the Chinese endemic seed flora. Biological Conservation, 198, 104-112.

Jiang H, Fan Q, Li JT, Shi S, Li SP, Liao WB, \& Shu WS. (2011). Naturalization of alien plants in China. Biodiversity and Conservation, 20(7), 1545-1556.

Liu X, Blackburn TM, Song T, Li X, Huang C, \& Li Y. (2019). Risks of biological invasion on the Belt and Road. Current Biology, 29(3), 499-505.

Lu LM, Mao LF, Yang T, Ye JF, Liu B, Li HL., ... Niu YT. (2018). Evolutionary history of the angiosperm flora of China. Nature, 554(7691), 234.

Ma JS, Yan XL, \& Shou HY. (2013). The checklist of the Chinese invasive plants. Beijing: China Higher Education Press.

Ma JS. (2014). The survey reports on Chinese alien invasive plants. Beijing: China Higher Education Press.

Ni, M. Deane, DC, ... Fnag SQ. (2021) Invasion success and impacts depend on different characteristics in non-native plants, in press.

Muggeo VMR. (2003). Estimating regression models with unknown break-points. Statistics in Medicine, 22(19) : 3055-3071. 


\section{Table}

\section{Table 1}

Identified break points and estimated slope (Estimate) and standard error (SE) of the segmented linear regression model for each of four periods identified. Slope values indicate the mean number of species introduced per year over the relevant period.

\begin{tabular}{|lll|}
\hline Period & Estimate & S.E. \\
\hline $1840-1904$ & 0.6457 & 0.0335 \\
\hline $1904-1935$ & 8.7651 & 0.1071 \\
\hline $1935-2002$ & 1.9854 & 0.0321 \\
\hline $2002-2011$ & 4.4286 & 0.3367 \\
\hline
\end{tabular}

\section{Figures}

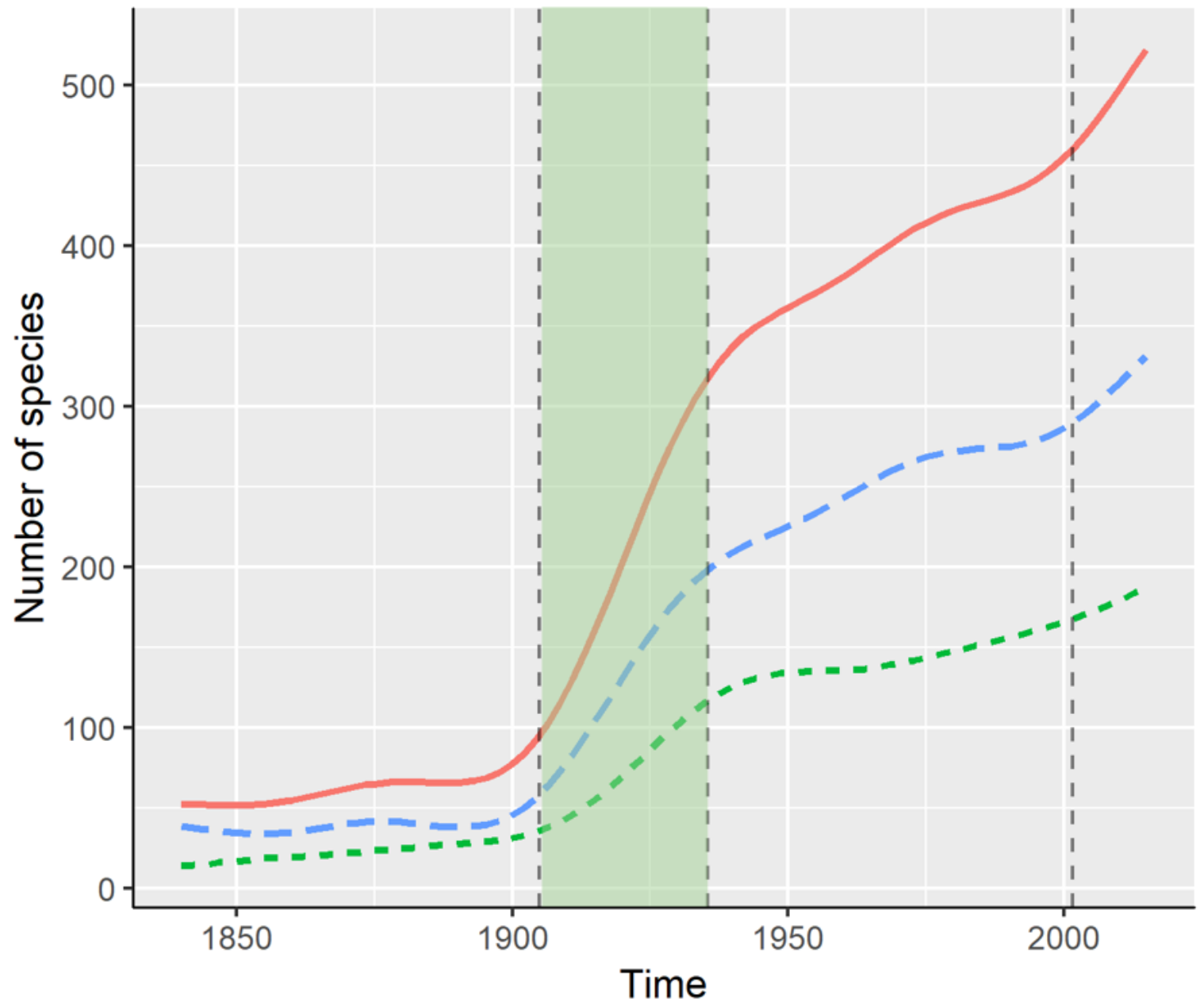

Introduction pathway

- all

$=$ unintentional

- ' intentional

Figure 1 
Cumulative number of introductions of non-native plants in China for all species and by introduction pathway. The cumulative curves were smoothed using a generalized additive model. The vertical dashed lines show the breakpoints of introduction rates estimated by segmented regression model. The shaded period of 1905-1935 was the time of the most rapid introduction of non-native plants in recorded history. See Table 1 for slope values for each segment.

\section{Supplementary Files}

This is a list of supplementary files associated with this preprint. Click to download.

- firstrecordtime.xlsx 